\title{
Dragonbox Algebra 5+ sebagai Media Pembelajaran Aljabar untuk Siswa Sekolah Dasar
}

\author{
Sisilia Sylviani ${ }^{1}$, Fahmi Candra Permana ${ }^{2}$ \\ 1) Departemen Matematika, FMIPA, Universitas Padjadjaran \\ Jl. Raya Bandung-Sumedang Km. 21, Jatinangor 45363 \\ Email: sisilia.sylviani@unpad.ac.id \\ 2) Program Studi Pendidikan Multimedia, Kampus UPI di Cibiru, Universitas Pendidikan Indonesia \\ Jl. Raya Cibiru Km 15 Bandung 40393 \\ Email: fahmi.candrap@upi.edu
}

\begin{abstract}
ABSTRAK
Dalam paper ini dibahas peran game online Dragonbox Algebra 5+ sebagai salah satu cara yang dapat dilakukan untuk meningkatkan minat siswa dalam pembelajaran matematika, khususnya aljabar. Di era digital yang berkembang begitu pesat ini, penggunaan hal-hal yang terkait dengan internet telah menjadi suatu hal yang menjadi kebutuhan sehari-hari. Apalagi dalam hal permainan atau game online. Tidak dapat dipungkiri bahwa sebagian besar anak-anak aktif dalam beberapa permainan atau game online. Oleh karena itu, hal tersebut dijadikan penulis sebagai salah satu sarana pembelajaran sebagai upaya untuk meningkatkan ketertarikan siswa terhadap aljabar. Metode ini dapat dijadikan sebagai salah satu upaya bagi pengajar dalam meningkatkan ketertarikan siswa kepada aljabar, yang pada akhirnya dapat meningkatkan keterlibatan serta pemahaman siswa dalam pelajaran tersebut.
\end{abstract}

Kata kunci: aljabar, Dragonbox Algebra 5+, matematika, pembelajaran, permainan

\begin{abstract}
This paper discusses the role of the Dragonbox Algebra 5+ online game as a way to increase student interest in learning mathematics, especially algebra. In this fast growing digital era, the use of things related to the internet has become a daily necessity. Especially in terms online games. It cannot be denied that most of the children are active in some online games. Therefore, it can be used by as a means of learning as an effort to increase students' interest in algebra. This method can be used as an effort for teachers to increase student interest in algebra, which in turn can increase student interaction and understanding in the lesson.
\end{abstract}

Keywords: algebra, Dragonbox Algebra 5+, games, learning, mathematics

\section{Pendahuluan}

Saat ini, internet telah menjadi sesuatu hal yang sangat penting dan bahkan digunakan hampir dalam setiap aspek kehidupan. Banyak aplikasi-aplikasi yang berbasis online dimanfaatkan dalam berbagai hal. Salah satunya adalah aplikasi yang dibangun berdasarkan kepercayaan rakyat jepang terkait golongan darah [3] Berdasarkan data dari Kementerian Komunikasi dan Informatika Republik Indonesia, studi yang didanai oleh UNICEF dan dilaksanakan oleh Kementerian Komunikasi dan Informatika (Kemkominfo) menemukan bahwa 98 persen dari anak-anak dan remaja tahu tentang internet dan 79,5 persen diantaranya adalah pengguna internet. Kepala Pusat Informasi dan Humas Kementerian Kominfo Gatot S Dewabroto menyatakan, temuan ini hasil dari kesimpulan utama yang menelusuri aktivitas online dari sample anak dan remaja usia 10-19 tahun dengan 400 responden yang tersebar di seluruh wilayah perkotaan dan pedesaan. Studi dibangun berdasarkan pada penelitian sebelumnya sehingga didapatkan gambaran yang paling komprehensif dan terkini tentang penggunaan media digital di kalangan anak-anak dan remaja Indonesia, termasuk motivasi mereka, serta informasi tentang anak remaja berusia 10-19 yang tidak menggunakan media digital. Penelitian ini baru pertama kali dilakukan dibandingkan penelitian serupa lainnya di Indonesia, kata Gatot, Selasa (18/2). (https://kominfo.go.id/index.php/content/detail/3836/98+Persen+Anak+ dan+Remaja+Tahu+Internet/0/berita_satker). 
Hasil studi bahkan menunjukkan, mayoritas aktivitas yang dilakukan masyarakat melalui smartphone yaitu bermain gim (25\%). Mereka rata-rata bermain gim mobile dengan durasi 53 menit. Aktivitas lainnya yang dilakukan pengguna dengan smartphone yaitu bersosial media (17\%), streaming video (12\%), browsing (10\%), hingga berbelanja online (7\%). Dari sisi usia, gamer di Indonesia tak hanya digandrungi oleh kalangan muda saja. Studi menunjukkan seperempat dari jumlah total gamer memiliki usia 16-24 tahun dan 25-34 tahun, dimana persentasenya masing-masing 27 persen. 24 persen lainnya tercatat berusia 35-44 tahun. Pengguna smartphone dengan usia 45-54 tahun juga turut aktif memainkan gim mobile dengan persentase 17 persen dari basis gamer di Indonesia. (https://www.tek.id/insight/jumlah-gamer-di-indonesia-capai-100-juta-di-2020b1U7v9c4A). Bahkan anak pada usia sekolah dasar pun banyak menyukai game online, walaupun jenis dari game yang mereka mainkan berbeda genre dengan yang dimainkan oleh anak-anak usia di atasnya.

Saat bermain game, anak-anak dapat bertahan bahkan hingga berjam-jam. Bahkan untuk kasus ekstrim, mereka ada yang dapat seharian bermain game. Oleh karena itu, dengan fenomena tersebut game dapat dimanfaatkan sebagai media pembelajaran, khususnya dalam hal ini untuk pelajaran aljabar. Hal yang cukup kontras terlihat adalah kebanyakan anak mudah bosan pada saat mereka belajar matematika, khususnya konsep aljabar. Mereka cenderung cepat bosan dan menyerah apabila terdapat hal yang mereka tidak pahami pada saat proses pembelajaran tersebut. Berbeda halnya dengan game, dimana saat mereka mengalami kekalahan saat melakukan permainan tertentu, mereka justru menjadi tertantang untuk dapat memenangkan permainan tersebut.

Beberapa peneliti telah banyak melakukan penelitian terkait pemanfaatan game sebagai metode pembelajaran. Terdapat beberapa hal yang melatarbelakangi hal tersebut. Salah satunya adalah karena game dapat melibatkan berbagai aktivitas pembelajaran individu dan sosial, para pendukung berpendapat bahwa game adalah media yang ideal untuk belajar dan ini adalah upaya untuk meningkatkan pembelajaran melalui aktivitas menyenangkan yang berkelanjutan di lingkungan digital kita saat ini [4].

Kebritchi pada tahun 2008 [7], dalam papernya, menyebutkan bahawa permainan instruksional (termasuk permainan simulasi dan permainan komputer yang dirancang khusus untuk pembelajaran pendidikan) telah menghasilkan minat dalam pendidikan untuk dimanfaatkan sebagai alat untuk mempromosikan pembelajaran. Saat teknologi terus berkembang, banyak studi atu penelitian menemukan bahwa potensi menggabungkan pembelajaran konvensional melalui pembelajaran Game simulasi dapat memberikan kontribusi terhadap peningkatan minat dan pembelajaran siswa (lihat [2], [5],dan [7]).

Banyak peneliti pendidikan matematika telah mengemukakan bahwa konsep aljabar dapat diperkenalkan sejak dini (Radford, 2007, 2012, Mulligan \& Mitchelmore 2009, Highfield \& Mulligan, 2007). Meskipun Radford (2007) menyoroti itu bahwa berpikir aljabar untuk usia dini atau anak-anak lebih difokuskan kepada pengembangan pemahaman tentang pola tertentu. Beberapa penelitian telah menyebutkan terkait pemanfaat teknologi, khususnya internet, dalam pembelajaran matematika. Diantaranya ada yang memanfaatkan Phet simulation [12] yang merupakan aplikasi terbuka yang online, dan adapula yang menggunakan software berbayar seperti maple [11] yang berbayar namun memiliki perangkat yang lengkap. Untuk itu dalam paper ini dibahas pemanfaatan game online dragonbox algebra 5+ sebagai media pembelajaran aljabar, khususnya untuk siswa sekolah dasar.

\section{Metode Penelitian}

Metodologi yang digunakan oleh penulis adalah studi literatur dari berbagai sumber baik buku-buku serta jurnal-jurnal. Jurnal-jurnal digunakan sebagai referensi terkait metode pembelajaran yang menggunakan metode game sebagai medianya. Referensi lain yang digunakan adalah halaman web dari pengembang permainan atau game online, khusunya game dragonbox algebra 5+. Adapaun hal yang ditinjau lebih dalam adalah penggunaan game online dragonbox algebra 5+ dalam meningkatkan pemahaman siswa pada konsep aljabar.

\section{Studi literatur}

Kajian-kajian literatur yang dilakukan oleh penulis diantaranya adalah sebagai berikut.

\section{Pembelajaran berbasis Game}

Salen dan Zimmerman [10] mendefinisikan game atau permainan sebagai "sistem di mana pemain terlibat 
konflik buatan, yang ditentukan oleh aturan, yang menghasilkan hasil yang dapat diukur ". Pembelajaran berbasis game memiliki kemiripan dengan pembelajaran menyenangkan atau yang dikenal dengan playful learning. Tabel 1 membandingkan pembelajaran berbasis permainan dengan dua pendekatan lain, yaitu gamifikasi dan pembelajaran menyenangkan. Gamifikasi melibatkan penambahan fitur permainan tertentu, terutama yang melibatkan sistem penghargaan dan struktur naratif, ke lingkungan belajar (nongame) yang ada agar lebih memotivasi. Gamifikasi melibatkan penambahan insentif seperti bintang, poin, pencapaian, atau peringkat untuk mendorong pelajar agar mengerahkan upaya pada tugas lain yang kurang mereka minati.

Tabel 1. Perbandingan Gamification, Playful Learning, dan Game Based Learning [6]

\begin{tabular}{|c|c|c|c|}
\hline & Learning Activity & Game features & Example \\
\hline Gamification & Largely unchanged & $\begin{array}{l}\text { Mostly use of extrinsic } \\
\text { rewards }\end{array}$ & Gamified worksheets \\
\hline Playful learning & $\begin{array}{l}\text { Redesigned to be more } \\
\text { relevant, meaningful, } \\
\text { and interesting }\end{array}$ & $\begin{array}{l}\text { Mostly use of } \\
\text { intrinsic rewards }\end{array}$ & $\begin{array}{l}\text { Simulation with } \\
\text { playful feedback }\end{array}$ \\
\hline Game-based learning & $\begin{array}{l}\text { Redesigned to be more } \\
\text { relevant, meaningful, } \\
\text { and interesting }\end{array}$ & $\begin{array}{l}\text { Use of full range of } \\
\text { game features }\end{array}$ & Learning game \\
\hline
\end{tabular}

Berbeda dengan gamification, pembelajaran berbasis game berarti tugas pembelajaran dirancang ulang agar lebih menarik, bermakna dan pada akhirnya, lebih efektif untuk pembelajaran daripada tugas nongame atau gamified. Desain ulang ini didasarkan pada wawasan dari pendidikan, pedagogi, dan ilmu pembelajaran, serta dari teori dan penelitian disiplin ilmu tertentu [8]. Hasilnya mencakup pedagogi baru dan cara belajar baru yang, jika berhasil, tidak hanya akan dianggap sebagai tugas belajar yang baik tetapi juga permainan yang bagus.

Matematika dan sains telah menjadi fokus dari banyak pengembangan dan penelitian game, sebagian karena penekanan besar pada sains, teknologi, teknik, dan matematika (STEM) dalam kurikulum sekolah standar [9]. Potensi bermain untuk mendukung pembelajaran STEM ditemukan bahkan untuk siswa termuda. Sebagai contoh, permainan blok pada anak-anak prasekolah telah ditemukan untuk memprediksi prestasi akademis selanjutnya dalam matematika [14]. Secara umum, bermain dengan mainan spasial seperti balok, puzzle, dan permainan bentuk mendukung pengembangan keterampilan spasial dan terkait dengan kesiapan sekolah, terutama untuk area STEM [13].

Devlin [1] menyatakan bahwa pembelajaran matematika dari buku menghambat kemampuan peserta didik untuk mengembangkan pemikiran matematis, karena sangat berfokus pada penguasaan keterampilan dan bukan konsep. Dia berpendapat bahwa game dapat menyediakan lingkungan yang ideal untuk belajar matematika karena dapat menempatkan pembelajaran matematika dalam konteks, sehingga memudahkan pelajar untuk memahami konsep matematika dan situasi di mana mereka akan diterapkan. Lingkungan belajar yang tersedia dalam game dapat dibentuk sedemikian rupa sehingga memungkinkan perancang pendidikan untuk menanamkan prinsip-prinsip matematika di lingkungan dan mengalami pembelajaran yang dikontekstualisasikan. Game dapat memberikan "makna" angka, yang memotivasi pemain untuk mengembangkan penguasaan agar berhasil dalam permainan.

\section{DragonBox}

Game Dragonbox diciptakan oleh perusahaan " We want to know". Game ini tersedia pada platform computer dan juga smartphone. Terdapat dua versi berbeda dari game ini berdasarkan peruntukkannnya, yaitu Dragonbox Algebra 5+, yang ditujukan untuk anak-anak 5 tahun ke atas, dan Dragonbox 12+ yang ditujukan untuk anak-anak 12 tahun dan lebih.

Pada tahun 2011, konsep pertama Dragonbox Algebra (sekarang Dragonbox Algebra 5+) mulai berkembang. Ide awalnya adalah untuk membuat alat belajar yang mempercepat dan mempermudah untuk mempelajari aljabar. Diciptakan sebagai game yang "diam-diam mengajarkan aljabar", aplikasi inovatif ini mendapatkan pengakuan internasional sebagai salah satu game serius terbaik 
yang pernah ada, dan pengubah permainan untuk cara pengajaran matematika (https://dragonbox.com/about/our-story).

Sejak game aljabar pertama diluncurkan pada tahun 2012, WeWantToKnow telah mengembangkan seri ini dengan menyertakan lima game menyenangkan dan mendidik. Anak-anak dapat menjelajahi dua permainan aljabar, dengan tingkat kesulitan yang bervariasi - Aljabar Dragonbox Algebra 5+ dan 12+. Siswa dapat menemukan dunia geometri dengan DragonBox Elements. Pada tahun 2015, DragonBox Number diperkenalkan, yang mengajarkan anak-anak pengertian angka, serta penjumlahan dan pengurangan dasar. Game terbarunya, DragonBox BIG Numbers, dirilis pada November 2016. Seiring berlalunya waktu, game juga telah berkembang. Seri DragonBox Algebra dan DragonBox Element diciptakan untuk menjadi permainan yang cepat dan efektif yang akan membuat pembelajaran tidak terlalu sulit bagi siswa, guru, dan orang tua. Game yang lebih baru, DragonBox Numbers dan DragonBox BIG Numbers adalah game yang lebih panjang yang dibuat untuk melibatkan siswa dan menciptakan pemahaman yang lebih dalam tentang konsep di luar teknik menghafal yang biasa dilakukan. Waktu bermain jauh lebih lama daripada aplikasi sebelumnya.

Sebagai orang tua, tim dari game Dragonbox memahami betapa pentingnya waktu layar anak yang terbatas diisi dengan konten berkualitas. Salah satu faktor pendorong saat mengembangkan game DragonBox adalah menggabungkan kesenangan yang dicari seorang anak dari tablet atau smartphone, dengan pendidikan yang mereka butuhkan untuk keberhasilan mereka di masa depan.

Dragonbox juga telah memperoleh banyak penghargaan. Penghargaan yang diperoleh Dragonbox Algebra 5+ adalah Gold Medal - 2012 International Serious Play Conference, Best Educational Game 2012 - Fun and Serious Games Festival, Best Serious Mobile Game - 2012 Serious Games Showcase \& Challenge, App of the Year \& Children's App of the Year - GullTasten 2012 [NORWEGIAN], Best Serious Game - 9th International Mobile Gaming Awards (2012 IMGA), ON for Learning Award Common Sense Media 2013, dan Editor's Choice Award - Children's Technology Review 2013. Adapun penghargaan yang diperoleh Dragonbox Algebra 12+ adalah ON for Learning Award - Common Sense Media 2013, Best Pick App - Tech with Kids 2013, Best Nordic Innovation Award - Nordic Game Awards 2013, Best App for Teaching \& Learning - 2014 American Association of School Librarians.

\section{Implementasi Dragonbox Algebra}

Pemain diperkenalkan ke ubin yang berbeda dan mengatakan bahwa setiap ubin memiliki "sisi gelap (Dark Side)", yang mewakili " angka negative (Negative number)". Ketika satu ubin "adil (fair)" dipasangkan dengan ubin dengan motif yang sama, namun dengan "sisi gelap (dar" menghadap ke atas - a "Pusaran hijau (Green Vortex)" muncul, yang mewakili nol (lihat gambar 1 dan tabel 2). Perusahaan WeWant to Know mengklaim bahwa ini mengajarkan pemain sifat inverse Aditif $(a+(-a)=0)$ dan sifat Identitas Aditif Properti $(a+0=a)$.

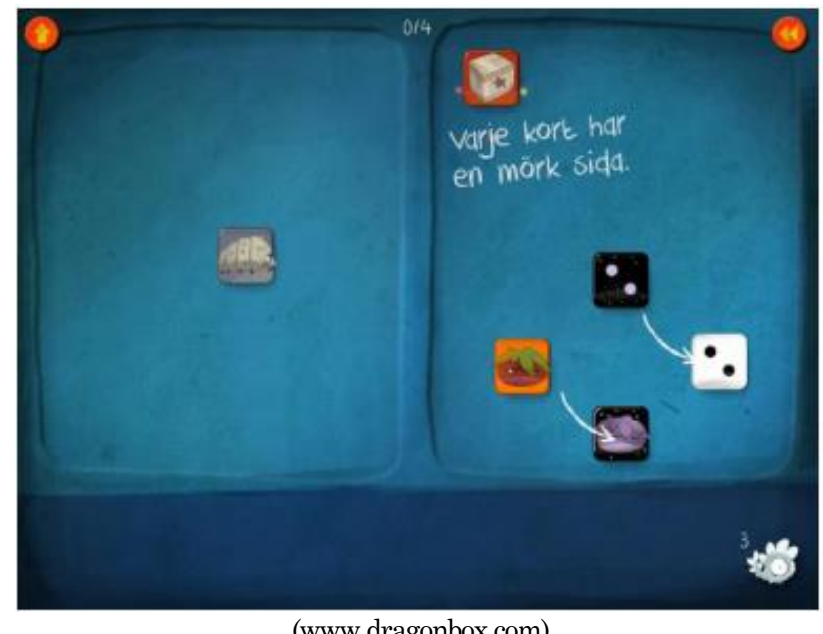

Gambar 1. Ubin gelap / cerah (the dark/the fair tile); Level 1-Sublevel 
Saat bermain, suatu "aksi (action)" baru diperkenalkan dengan interval dari empat hingga delapan sublevel. Aksi-aksi tersebut termasuk di dalamnya kegiatan menambahkan ekstra ubin atau mengalikan factorfaktornya. Menurut pihak pengembang (WeWanttoKnow), setiap tindakan mengajar pemain aturan aljabar. Pada game Dragonbox Algebra 5+ ini terdapat totalnya 5 level, setiap level berisi 20 sublevel. Untuk setiap level ada naga yang berevelosusi sedikit demi sedikit sesuai dengan setiap selesainya sublevel.

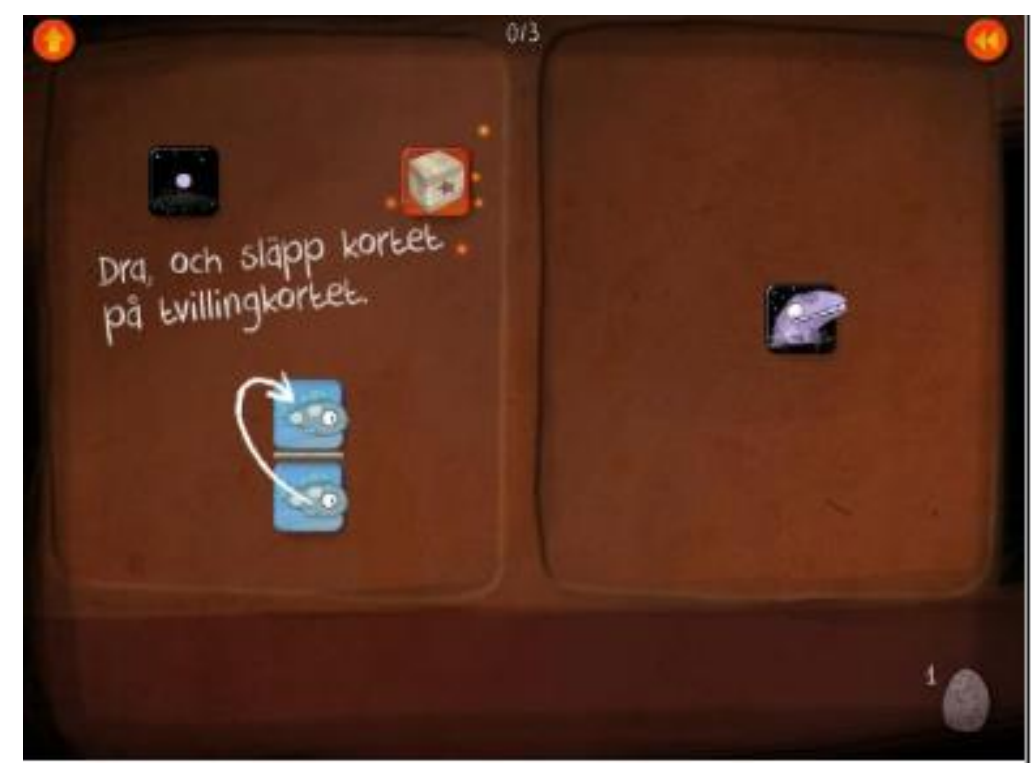

(www.dragonbox.com)

Gambar 2. Pecahan (Fractions); sublevel 1

Pada Gambar 2 di atas pemain diperkenalkan ke bar pecahan (Fraction) dan sifat inverse perkalian $(a \cdot(1 / a)=1)$.

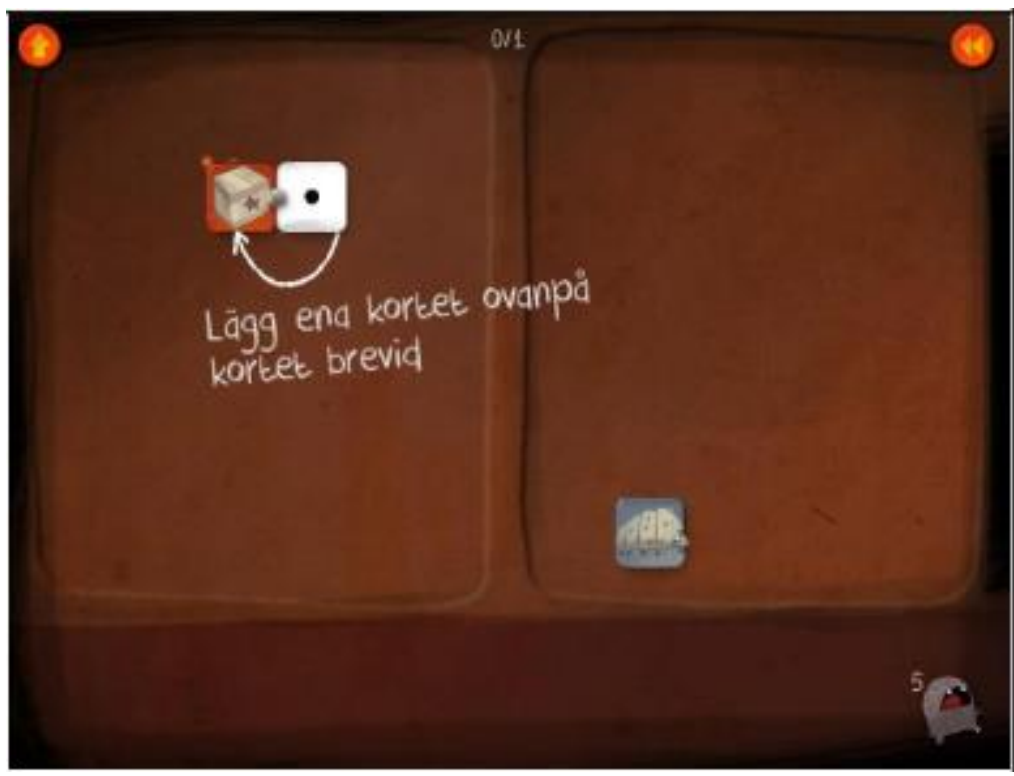

(www.dragonbox.com)

Gambar 3. Perkalian (Multiplications); level 2-sublevel 5

SIfat Identitas diperkenalkan hanya empat sublevel setelah itu, seperti yang ditunjukkan pada Gambar 3 di atas. Selama sisa permainan di level 2 dan level 3, tidak ada sifat baru yang disajikan, namun pada level tersebut disajikan perpaduan sifat-sifat yang disajikan dalam bentuk-bentuk yang berbeda. 


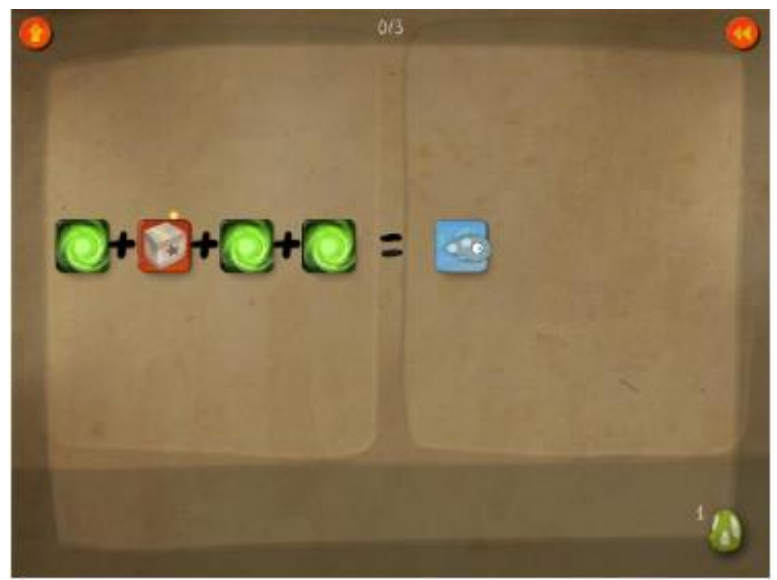

(www.dragonbox.com)

Gambar 4. Ubin kalimat (Tile Sentence); Level 4-sublevel 1

Pada sublevel pertama di level 4, pemain disajikan kalimat angka pertama (persamaan) dan tanda persamaan pertama, meskipun itu dibuat oleh ubin (tiles), bukan angka atau variabel (lihat Gambar 4). Selama level 4 sublevel berevolusi atau berkembang dari ubin gambar ke dadu dan di sublevel terakhir disajikan variabel dan angka.

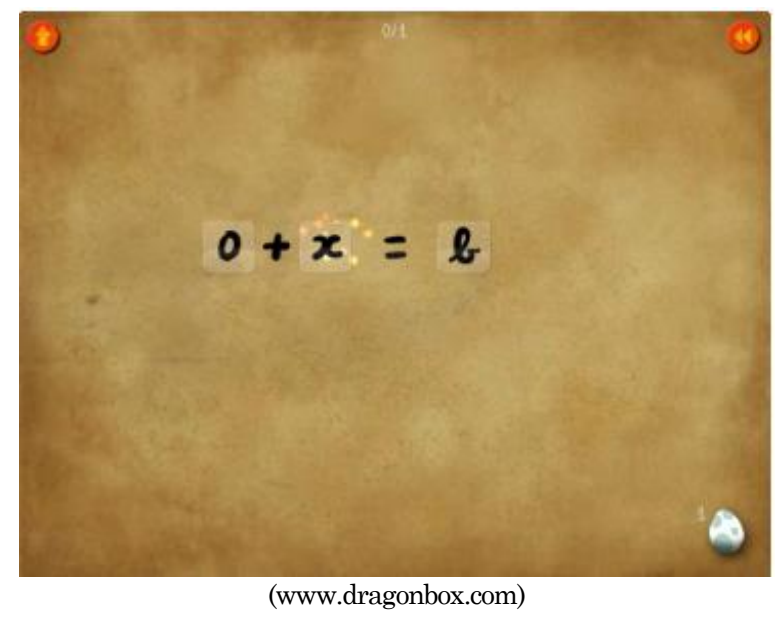

Gambar 5. Kalimat angka (Number Sentence); Level 5-Sublevel 1

Di level terakhir - level lima - sisi-sisi pada background menghilang dan semua level hanya menggunakan ubin huruf dan nomor (lihat Gambar 5).

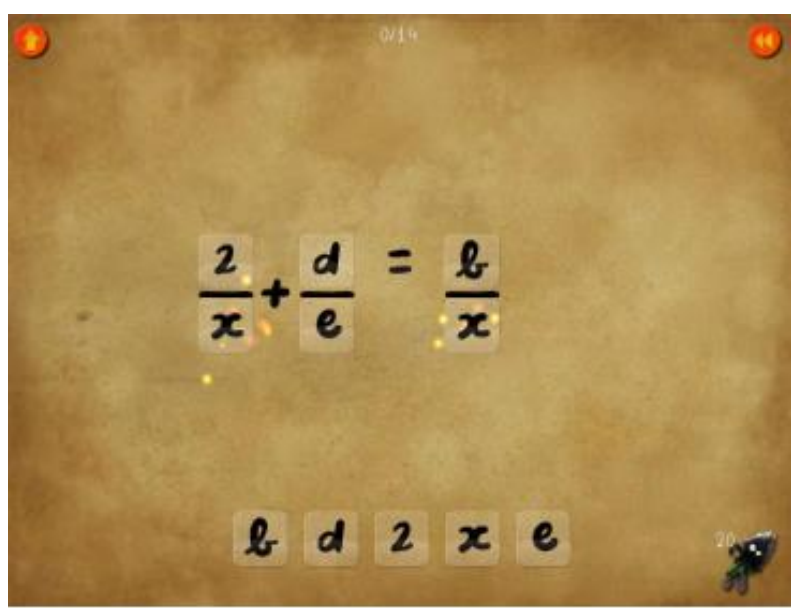

(www.dragonbox.com)

Gambar 6. Persamaan (Equation); Level 5-Subleve 20 
Di akhir versi $5+$, pemain ditantang dengan permasalahan pecahan dan persamaan matematika seperti yang terlihat pada gambar 6 .

Tabel 2. Ubin-ubin (tiles) pada Dragonbox Algebra 5+

\begin{tabular}{|c|c|c|c|c|}
\hline Ubin (tile) & Sisi Fair/Positif & $\begin{array}{c}\text { Diperkenalkan } \\
\text { pada } \\
\text { sublevel/level }\end{array}$ & $\begin{array}{c}\text { Sisi } \\
\text { gelap/negatif } \\
\text { (dark/negative } \\
\text { side) }\end{array}$ & $\begin{array}{c}\text { Diperkenalkan } \\
\text { pada } \\
\text { sublevel/level }\end{array}$ \\
\hline Box & & Dari awal & & $\begin{array}{l}\text { Level } 2 \\
\text { Sublevel } 3\end{array}$ \\
\hline $\begin{array}{l}\text { Pusaran hijau } \\
\text { (Green Vortex) }\end{array}$ & & Dari awal & - & - \\
\hline $\begin{array}{l}\text { Gambar } \\
\text { (contoh) }\end{array}$ & & $\begin{array}{l}\text { Level } 1 \\
\text { Sublevel } 2\end{array}$ & & $\begin{array}{l}\text { Level } 1 \\
\text { Sublevel } 3\end{array}$ \\
\hline Dadu (contoh) & & $\begin{array}{l}\text { Level } 1 \\
\text { Sublevel } 3\end{array}$ & & $\begin{array}{l}\text { Level } 1 \\
\text { Sublevel } 3\end{array}$ \\
\hline $\begin{array}{l}\text { Huruf-huruf } \\
\text { (contoh) }\end{array}$ & & $\begin{array}{l}\text { Level } 1 \\
\text { Sublevel } 12\end{array}$ & & $\begin{array}{l}\text { Level } 1 \\
\text { Sublevel } 12\end{array}$ \\
\hline $\begin{array}{c}\text { X sebagai yang } \\
\text { tidak } \\
\text { diketahui } \\
\text { (Unknown) }\end{array}$ & & $\begin{array}{l}\text { Level } 1 \\
\text { Sublevel } 18\end{array}$ & & $\begin{array}{l}\text { Level } 5 \\
\text { Sublevel } 16\end{array}$ \\
\hline 0 & & $\begin{array}{l}\text { Level } 2 \\
\text { Sublevel } 20\end{array}$ & - & - \\
\hline $\begin{array}{c}\text { Angka-angka } \\
\text { (numbers) }\end{array}$ & & $\begin{array}{l}\text { Level } 3 \\
\text { Sublevel } 14\end{array}$ & & $\begin{array}{l}\text { Level } 3 \\
\text { Sublevel } 15\end{array}$ \\
\hline
\end{tabular}

Tabel 2. merangkum ubin (tiles) mana yang diperkenalkan pada saat permainan.

\section{Simpulan}

Aljabar sering kali dianggap sebagai suatu hal yang tidak disukai oleh anak-anak. Ada yang mengganggpnya sulit untuk dipahami, menakutkan, dan lain sebagainya. Dengan adanya anggapan tersebut, menjadikan aljabar sebagai sesuatu yang terkadang sulit dipahami oleh anak-anak. Untuk itu, sebagai salah satu upaya dalam meningkatkan minat anak-anak untuk belajar aljabar adalah dengan menggunakan metode pembelajaran yang dapat diterima oleh anak-anak. Di era internet saat ini, game merupakan hal yang sangat diminati oleh berbagai kalangan, khususnya anak-anak. Banyak diantara anak-anak yang dapat menghabiskan waktu yang cukup lama untuk bermain game online. Untuk itu, dengan memanfaatkaan fenomena tersebut, digunakan game online Dragonbox Algebra 5+ yang didesain sebagai permainan yang memasukan konsep-konsep aljabar di dalamnya. Dengan menggunakan Dragonbox Algebra 5+ ini, anak-anak dapat menerima konsep-konsep aljabar dengan cara yang tidak membosankan bahkan menyenangkan bagi mereka. Hal tersebut dapat mengarahkan mudah diterimanya konsep-konsep aljabar oleh mereka yang pada akhirnya memudahkan mereka untuk memahami konsep-konsep tersebut. 


\section{Daftar Pustaka}

1. Devlin, K. (2011). Mathe Matics Education For A New Era: Video Games As A Medium For Learning. Bocaraton, Fl: Crc Press.

2. Divjak, b., \& tomić, d. (2011). The impact of game-based learning on the achievement of learning goals and motivation for learning mathematics-literature review. Journal of information and organizational sciences, 35(1), 15-30.

3. Fahmi Candra Permana, Ayung Candra Padmasari, Sisilia Sylviani. Rancang Bangun Aplikasi Pendeteksi Jenis Golongan Darah Berdasarkan Konsep Kepercayaan Rakyat Jepang (Minkan Shinkō), Edsence: Jurnal Pendidikan Multimedia 1 (1), 25-34, 2019

4. Gee, J. P. (2007). What video games have to teach us about learning and literacy (2nd ed.). New York, NY: Palgrave Macmillan.

5. Hays, R. T. (2005). The effectiveness of instructional games: a literature review and discussion (no. Nawctsd-tr-2005-004). Naval air warfare center training systems div orlando fl.

6. Jan L. Plass, Richard E. Mayer, And Bruce D. HomerHandbook of Game- Based Learning The MIT Press Cambridge, Massachusetts , London 2019

7. Kebritchi,,F. (2008). Computer games application within alternative classroom goal structures: cognitive, metacognitive, and affective evaluation. Educational technology research and development, $56(5-6), 539-556$.

8. Plass, J. L., Milne, C., Homer, B. D., Schwartz, R. N., Hayward, E. O., Jordan, T., Barrientos, J. (2012). Investigating The Effectiveness Of Computer Simulations For Chemistry Learning. Journal Of Research In Science Teaching, 49(3), 394-419.

9. Porter, A., Mcmaken, J., Hwang, J., \& Yang, R. (2011). Common Core Standards: The New Us Intended Curriculum. Educational Researcher, 40(3), 103-116.

10. Salen, K., \& Zimmerman, E. (2004). Rules Of Play: Game Design Fundamentals. Cambridge, Ma: Mit Press.

11. Sisilia Sylviani, Fahmi Candra Permana, Dian Rinjani. Penggunaan Maple dalam Upaya Peningkatan Minat Siswa SMA dalam Pembelajaran Materi Integral. 1 (2), 61-70, 2019

12. Sisilia Sylviani, Fahmi Candra Permana, Rio Guntur Utomo. PHET Simulation sebagai Alat Bantu Siswa Sekolah Dasar dalam Proses Belajar Mengajar Mata Pelajaran Matematika, Edsence: Jurnal Pendidikan Multimedia 2 (1), 1-10, 2020

13. Verdine, B. N., Golinkoff, R. M., Hirsh- Pasek, K., \& Newcombe, N. S. (2014). Finding The Missing Piece: Blocks, Puzzles, And Shapes Fuel School Readiness. Trends In Neuroscience And Education, 3(1), 7-13.

14. Wolfgang, C. H., Stannard, L. L., \& Jones, I. (2001). Block Play Per For Mance Among Preschoolers As A Predictor Of Later School Achievement In Mathe Matics. Journal Of Research In Childhood Education, 15(2), 173-180. 